\title{
Protective Effects of Vitamin E Analogs against Carbon Tetrachloride-Induced Fatty Liver in Rats
}

\author{
Rieko Yachi' ${ }^{1}$ Osamu Igarashi² ${ }^{2}$ and Chikako Kiyose ${ }^{1,2, *}$ \\ 'Department of Applied Chemistry, Graduate School of Kanagawa Institute of Technology, \\ Kanagawa 243-0292, Japan \\ ${ }^{2}$ Department of Nutrition and Life Science, Kanagawa Institute of Technology, Kanagawa 243-0292, Japan
}

Received 5 April, 2010; Accepted 18 May, 2010; Published online 6 August, 2010

\begin{abstract}
Summary Recently, it has been reported that $\alpha$-tocopherol ( $\alpha$-Toc) is effective for amelioration of liver damage. However, it is unknown whether other vitamin $E$ analogs are effective. In this study, we investigated the effects of $\gamma$-tocopherol $(\gamma$-Toc) and tocotrienols (T3) in rats with fatty liver. Rats fed a vitamin E-deficient diet for four weeks were divided into eight groups: Control, carbon tetrachloride $\left(\mathrm{CCl}_{4}\right)$, $\alpha$-Toc, $\alpha$-Toc $+\mathrm{CCl}_{4}, \gamma$-Toc, $\gamma$-Toc $+\mathrm{CCl}_{4}, \mathrm{T3}$ mix, T3 mix $+\mathrm{CCl}_{4}$. After a $24 \mathrm{~h}$ fast, the rats were administered $20 \mathrm{mg}$ of each of the vitamin $\mathrm{E}$ analogs, respectively. Moreover, the $\mathrm{CCl}_{4}$ group were given $0.5 \mathrm{ml} / \mathrm{kg}$ body weight corn oil preparation containing $\mathrm{CCl}_{4} 6 \mathrm{~h}$ after vitamin $\mathrm{E}$ administration. We measured the activities of aspartate aminotransferase and alanine aminotransferase (ALT) in plasma, and the contents of triglyceride (TG), total cholesterol (T-Chol) and vitamin E analogs in the liver. Also, we determined the hepatic expression of mRNA for inflammatory cytokines. The liver TG content in the $\gamma$-Toc $+\mathrm{CCl}_{4}$ and $\mathrm{T3}$ mix $+\mathrm{CCl}_{4}$ groups was decreased in comparison with the $\mathrm{CCl}_{4}$ group. Moreover, ALT activity in the $\mathrm{T} 3 \mathrm{mix}+\mathrm{CCl}_{4}$ group was significantly lower than $\mathrm{CCl}_{4}$ group. These findings suggest that $\gamma$-Toc and T3 are effective for amelioration of fatty liver.
\end{abstract}

Key Words: $\gamma$-tocopherol, tocotrienol, fatty liver, carbon tetrachloride

\section{Introduction}

Carbon tetrachloride $\left(\mathrm{CCl}_{4}\right)$ is a chemical agent widely used for experimental induction of fatty liver and liver fibrosis in animals [1]. It is considered that $\mathrm{CCl}_{4}$ is metabolized by cytochrome P-450 (CYP) to unstable trichloromethyl free radicals (e.g. $\mathrm{CCl}_{3}, \mathrm{CCl}_{3} \mathrm{O}_{2}$ ), which then bind covalently to membrane proteins, finally causing lipid peroxidation [1-4]. The activities of aspartate aminotransferase (AST) and alanine aminotransferase (ALT) in rat plasma rise remarkably with hepatocyte necrosis and lipid accumulation when $\mathrm{CCl}_{4}$ is administered to rats. Therefore, this model is used widely to induce various fatty liver states.

\footnotetext{
*To whom correspondence should be addressed.

Tel: +81-46-291-3178 Fax: +81-46-291-3178

E-mail: kiyose@bio.kanagawa-it.ac.jp
}

Vitamin $\mathrm{E}$ is present naturally in the form of eight analogs, each differing in the number and position of the methyl groups on the chroman ring and by the presence or absence of a double bond on the phytyl side chain. One group, the tocopherols (Tocs), have a saturated phytyl side chain, and the other, the tocotrienols (T3s), have an unsaturated phytyl side chain. Each of the groups can occur in $\alpha-, \beta-, \gamma-$, or $\delta$-forms. Especially, $\alpha$ - and $\gamma$-Toc are abundant in vegetable oil and seeds such as almonds and peanuts, and act as lipid-soluble antioxidants in cell membranes, being important for maintenance of cell membrane fluidity. When administered orally, Toc analogs (especially $\alpha$ - and $\gamma$-Toc) are equally absorbed from the small intestine without discrimination. After uptake into intestinal cells, Toc analogs are integrated into chylomicrons. Chylomicron remnants are catabolized during circulation by lipoprotein lipase. After uptake of chylomicron remnants by the liver, Toc analogs are discriminated by $\alpha$-Toc transfer protein $(\alpha$-TTP) in the 
liver, which transports $\alpha$-Toc preferentially over $\gamma$-Toc into very-low-density lipoprotein (VLDL) during assembly [5]. Therefore, non $\alpha$-Toc $(\gamma$-Toc, T3) remains in the liver. Accordingly, we hypothesized that non $\alpha$-Toc may show function more effectively than $\alpha$-Toc in the liver. Some investigators have reported the effect of $\alpha$-Toc on liver injury induced by $\mathrm{CCl}_{4}$. It has already been reported that administration of $\alpha$-Toc or an $\alpha$-Toc-enriched diet suppresses the rise of plasma ALT activity and concentration of bilirubin induced by $\mathrm{CCl}_{4}[6,7]$, whereas non $\alpha$-Toc does not. In the present study we investigated the preventive effects of $\gamma$-Toc and T3 mix against lipid peroxidation, and also AST activities in $\mathrm{CCl}_{4}$-treated rats.

\section{Experimental Procedures}

\section{Animals and diets}

Male SD-IGS rats (six weeks old) were purchased from Charles River Japan, Inc. (Kanagawa, Japan). Forty rats were divided into eight groups: Control (C), $\mathrm{CCl}_{4}\left(\mathrm{CCl}_{4}\right)$, $\alpha$-Toc $(\alpha \mathrm{T}), \quad \alpha$-Toc $+\mathrm{CCl}_{4}\left(\alpha \mathrm{T}+\mathrm{CCl}_{4}\right), \quad \gamma$-Toc $(\gamma \mathrm{T}), \gamma$ $\mathrm{Toc}+\mathrm{CCl}_{4}\left(\gamma \mathrm{T}+\mathrm{CCl}_{4}\right), \quad \mathrm{T} 3 \quad \operatorname{mix}(\mathrm{T} 3), \quad \mathrm{T} 3 \mathrm{mix}+\mathrm{CCl}_{4}$ $\left(\mathrm{T} 3+\mathrm{CCl}_{4}\right)$. They were housed individually in stainless steel wire netting cages, and fed a commercial chow (Nippon Clea Co., Tokyo, Japan) for three days. The animals were kept in an environment controlled at $23 \pm 2{ }^{\circ} \mathrm{C}$ and $55 \pm 5 \%$ humidity, with a $12 \mathrm{~h} / 12 \mathrm{~h}$ light-dark cycle. Later, the rats were switched to a vitamin E-deficient diet for four weeks. This diet consisted of $8 \%$ vitamin E-deficient corn oil mixed with vitamin E-deficient feed (AIN76, Funabashi farm, Inc., Chiba, Japan). All experiments were conducted in accordance with the guidelines for the care and use of laboratory animals at Kanagawa Institute of Technology.

\section{Administration of vitamin E analogs and induction of liver damage by $\mathrm{CCl}_{4}$}

After $24 \mathrm{~h}$ of fasting, $20 \mathrm{mg}$ of each vitamin $\mathrm{E}$ analog was administered to the rats. The purity of T3 mix $(\alpha-\mathrm{T} 3 ; 37.8 \%$, $\beta$-T3; $4.0 \%, \gamma$-T3; 45.5\%, $\delta$-T3; 10.7\%) was $98 \%$. The purity of $\alpha$ - and $\gamma$-Toc were above $96.1 \%$ respectively. All vitamin $\mathrm{E}$ analogs were gifted by Eisai Food \& Chemical Co., Ltd. (Tokyo, Japan). Six hours later, a mixture of $\mathrm{CCl}_{4}$ and stripped corn oil $(1: 1,1 \mathrm{ml} / \mathrm{kg}$ body weight; $0.5 \mathrm{ml} / \mathrm{kg}$ body weight as $\mathrm{CCl}_{4}$ ) was administered orally to the rats. The control rats were given stripped corn oil alone as a placebo. After $6 \mathrm{~h}$ of $\mathrm{CCl}_{4}$ administration, all the rats were killed under diethyl ether anesthesia, and arterial blood, liver, adipose tissue, kidney, and adrenal gland were removed for analysis.

The plasma was separated from blood cells by centrifugation at 3,000 rpm for $10 \mathrm{~min}$. All tissues were immediately stored at $-80^{\circ} \mathrm{C}$ until analysis for biological parameters. Liver samples to be used for RNA isolation were soaked in
RNA later solution immediately and stored at $-80^{\circ} \mathrm{C}$. Liver samples to be used for histopathological examination were fixed in $10 \%$ formalin.

\section{Quantitative analysis of vitamin E analogs using HPLC}

The quantity of vitamin $\mathrm{E}$ in each organ was measured using Ueda's method [8]. A $0.1 \mathrm{~g}$ sample of each organ was homogenized with $0.9 \mathrm{ml}$ of $0.9 \% \mathrm{NaCl}$ (weight/vol) solution. The resulting homogenate $(0.1 \mathrm{ml})$ was pipetted into a $10 \mathrm{ml}$ centrifuge tube, and $50 \mu \mathrm{l}$ of $1,2,2,5,7,8$ pentamethyl-6-hydroxychroman (PMC, $1 \mu \mathrm{g} / \mathrm{ml}$ ) as an internal standard and $1.0 \mathrm{ml}$ of ethanolic pyrogallol $(6 \%$, weight/vol) were added to each tube with stirring. After $0.2 \mathrm{ml}$ of $60 \%$ (weight/vol) $\mathrm{KOH}$ solution had been added to each tube, the contents were saponified at $70^{\circ} \mathrm{C}$ for $30 \mathrm{~min}$. After cooling, vitamin $\mathrm{E}$ analogs were extracted with $4.5 \mathrm{ml}$ of $1 \%$ sodium chloride solution and $3.0 \mathrm{ml}$ of $10 \%$ ethyl acetate/n-hexane solution, and centrifuged at $3,000 \mathrm{rpm}$ at $4^{\circ} \mathrm{C}$ for $5 \mathrm{~min}$. A $2.0 \mathrm{ml}$ aliquot of the upper layer was evaporated, dissolved in $0.2 \mathrm{ml}$ of n-hexane, and subjected to HPLC. The HPLC system consisted of a pump, degasser, column oven, and detector (LC-20AD, DGU-20A3, CTO-20A and RF-10AXL, Shimadzu Co., Kyoto, Japan). The analytical conditions were as follows: column, Capcell pak NH2 column (4.6 mm I.D. ×250 mm; Shiseido, Tokyo, Japan); mobile phase, n-hexan-isopropanol (98:2); flow rate, $1.0 \mathrm{ml} / \mathrm{min}$; detection wavelength, $325 \mathrm{~nm}$.

\section{Measurement of liver damage markers and lipid concentra- tion in plasma}

AST and ALT activities and triglyceride (TG), total cholesterol (T-Chol) concentrations in plasma were measured using a biochemical autoanalyzer (CA-180; Furuno Electric Co., Ltd., Hyogo, Japan).

\section{Measurement of liver lipid content}

Total lipid in the liver was extracted by the method of Folch [9]. A $0.9 \mathrm{~g}$ sample of liver was ground with sodium sulfate and extracted with chloroform:methanol $=2: 1$, and then made up to $25 \mathrm{ml}$. A $125 \mu \mathrm{l}$ aliquot of the extract was added to $125 \mu \mathrm{l}$ of $1 \%$ TritonX-100 ethanol solution, followed by hearting at $50^{\circ} \mathrm{C}$ overnight, and then dissolved in $15 \mu \mathrm{l}$ of distilled water. TG and T-Chol concentrations in liver were measured using a biochemical autoanalyzer.

\section{Measurement of mRNA expression of inflammatory cytokines in liver}

Total RNA was extracted from liver tissues using RNAiso. The quantity and purity of the RNA were determined from the absorbance at $258 / 280 \mathrm{~nm}$. Total RNA was reversetranscribed into cDNA using a high-capacity RNA-to-cDNA kit in accordance with the manufacturer's protocol. 7500 Fast Real-Time PCR system and real time PCR kit (TaqMan ${ }^{\circledR}$ 
Table 1. Primer probe mixture of inflammatory cytokines and $\beta$-Actin

\begin{tabular}{lll}
\hline & Assay ID & Refseq \\
\hline Rat TNF- $\alpha$ & Rn99999009_m1 & NM_031512.1 \\
Rat IL1- $\beta$ & Rn99999011_m1 & NM_012589.1 \\
Rat IL6 & Rn99999017_m1 & NM_012675.2 \\
Rat $\beta$-actin & Rn00667869_m1 & NM_031144.2 \\
\hline
\end{tabular}

Assey ID and reference sequence number of primer probe mixtures used in TaqMan ${ }^{\circledR}$ Gene Expression Assays (Applied Biosystems).

Table 2. Thermal cycling condition

\begin{tabular}{cccc}
\hline & Step 1 & \multicolumn{2}{c}{ Step 2 } \\
\hline & Hold & \multicolumn{2}{c}{40 Cycle } \\
temperature & $95^{\circ} \mathrm{C}$ & $95^{\circ} \mathrm{C}$ & $60{ }^{\circ} \mathrm{C}$ \\
time & $20 \mathrm{~s}$ & $3 \mathrm{~s}$ & $30 \mathrm{~s}$ \\
\hline
\end{tabular}

Gene Expression Assays, Applied Biosystems Japan Ltd., Tokyo, Japan) were employed based on the manufacture's instruction. $\beta$-actin was used as an internal control. The content of the primer/probe mixture of inflammatory cytokines and $\beta$-actin is shown in Table 1 , and PCR thermal cycling conditions are shown in Table 2.

\section{Statistical analysis}

All data are expressed as the mean \pm SD. Statistical analysis was performed by one-way ANOVA, followed by Bonferroni post hoc test. Statistical analyses were performed using Kaleida Graph ver. 4 for Windows (Hulinks Inc.,
Tokyo, Japan). Differences were considered to be significant at $p<0.05$.

\section{Results}

\section{Liver weight and lipid content}

There were no significant differences in liver weight among the groups. The content of TG in liver was increased by administration of $\mathrm{CCl}_{4}$, but the increase was significantly suppressed by administration of T3. On the other hand, there were no significant differences in liver T-Chol content among the groups (Fig. 1). In addition, histopathological examination of the liver was performed after hematoxylineosin staining. Lipid accumulation in the liver was confirmed in the $\mathrm{CCl}_{4}$ group, $\alpha \mathrm{T}+\mathrm{CCl}_{4}$ group, $\gamma \mathrm{T}+\mathrm{CCl}_{4}$ group and $\mathrm{T} 3+\mathrm{CCl}_{4}$ group after administration of $\mathrm{CCl}_{4}$, but that in the $\mathrm{T} 3+\mathrm{CCl}_{4}$ group was lower than in the $\mathrm{CCl}_{4}$ group (Fig. 2).

\section{Activities of liver damage markers and lipid concentrations in plasma}

AST activity in plasma was increased by administration of $\mathrm{CCl}_{4}$, but this was unaffected by administration of vitamin $\mathrm{E}$ analogs. On the other hand, ALT activity also tended to increase after administration of $\mathrm{CCl}_{4}$. However, the rise in the plasma ALT level tended to be suppressed by $\gamma$-Toc administration, and T3 had a significant suppressive effect (Fig. 3). There were no significant differences in the TG and T-Chol concentrations in plasma among the groups (data not shown).
A)

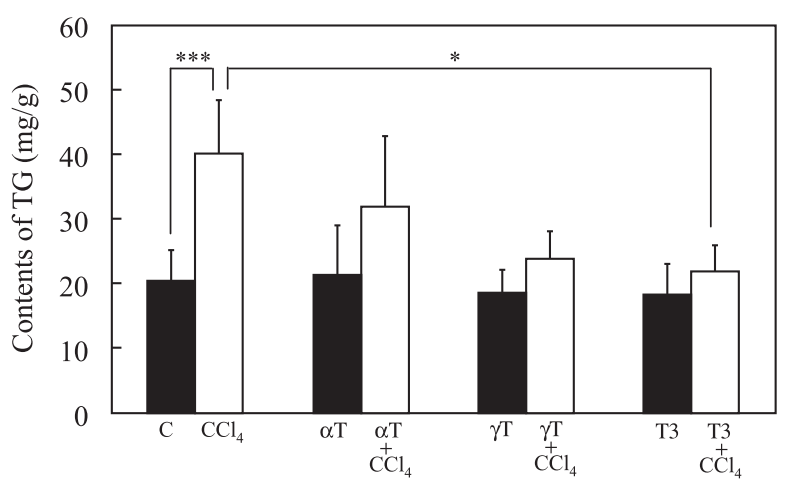

B)

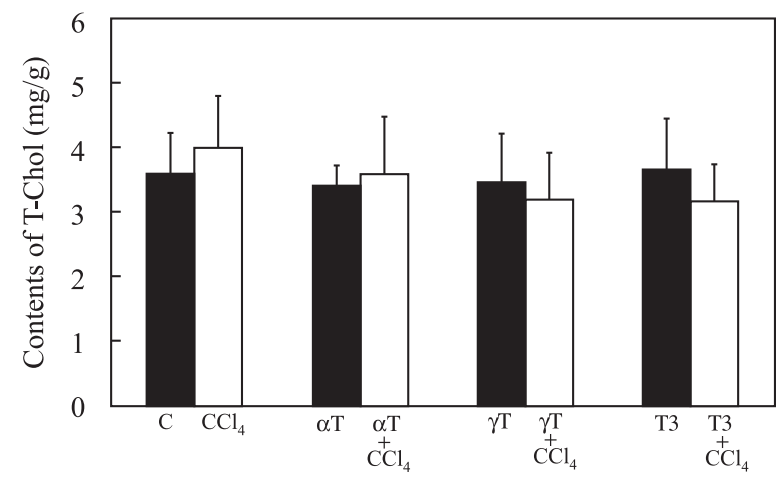

Fig. 1. Effects of vitamin $\mathrm{E}$ analogs on lipid contents of rat liver after administration of $\mathrm{CCl}_{4}$; (A) Liver TG content. (B) Liver T-Chol content. Rats were fed a vitamin E-deficient diet for four weeks. After a $24 \mathrm{~h}$ fast, $20 \mathrm{mg}$ of each vitamin $\mathrm{E}$ analog was administered. Six hours later, a mixture of $\mathrm{CCl}_{4}$ and stripped corn oil $\left(1: 1,1 \mathrm{ml} / \mathrm{kg}\right.$ body weight; $0.5 \mathrm{ml} / \mathrm{kg}$ body weight as $\left.\mathrm{CCl}_{4}\right)$ was orally administered to the rats. The control rats were given stripped corn oil alone as a placebo. Six hours after $\mathrm{CCl}_{4}$ admin-

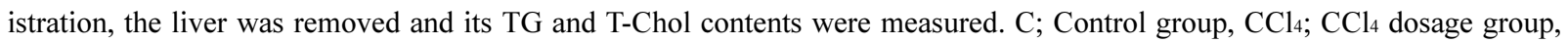
$\alpha \mathrm{T} ; \alpha$-Toc dosage group, $\alpha \mathrm{T}+\mathrm{CCl}_{4} ; \alpha$-Toc $+\mathrm{CCl}_{4}$ dosage group, $\gamma \mathrm{T} ; \gamma$-Toc dosage group, $\gamma \mathrm{T}+\mathrm{CCl}_{4} ; \gamma$-Toc $+\mathrm{CCl}_{4}$ dosage group, T3; T3 mix dosage group, T3 $+\mathrm{CCl}_{4}$; T3 mix $+\mathrm{CCl}_{4}$ dosage group. The values are mean $\pm \mathrm{SD}$ for 5 rats, ${ }^{*} p<0.05$, $* * * p<0.001$ (one-way ANOVA followed by Bonferroni post hoc test). 


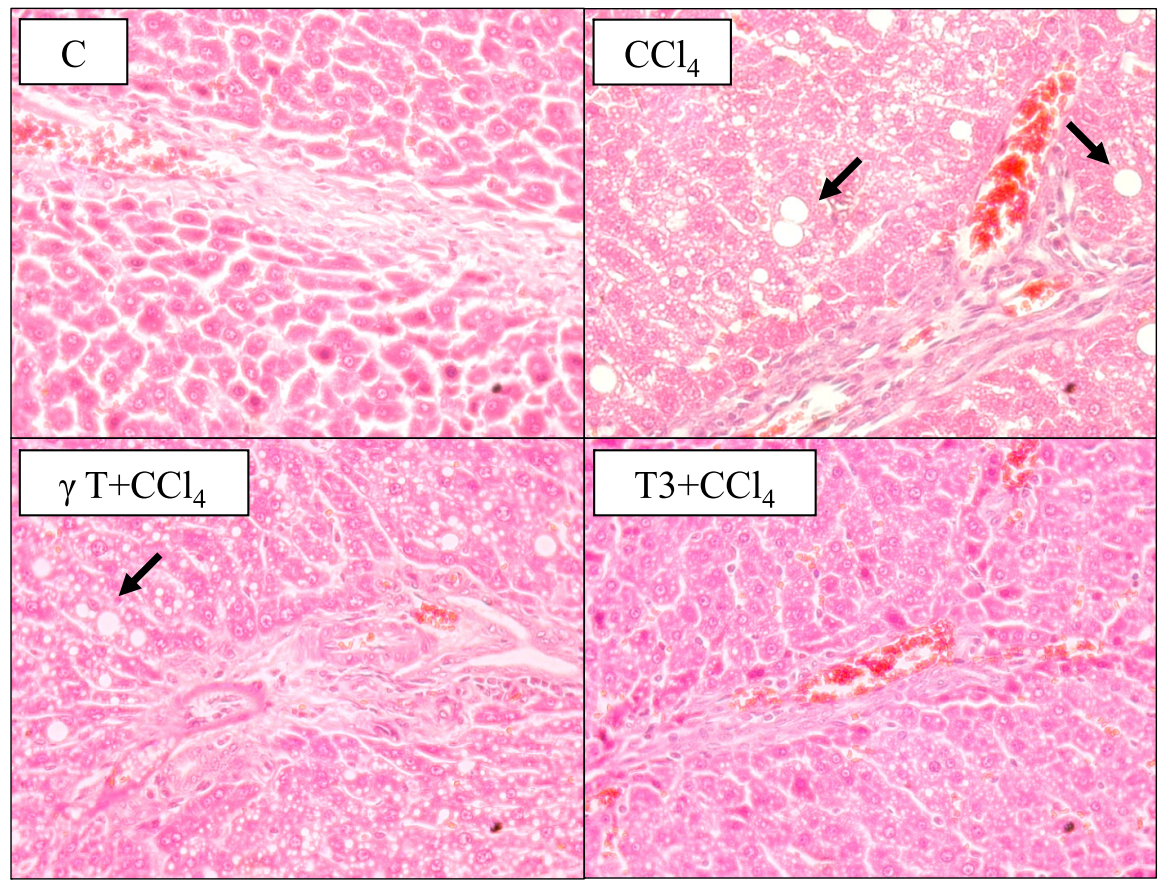

Fig. 2. Histopathology of rat liver after administration of $\mathrm{CCl}_{4}$. C; Control group, $\mathrm{CCl}_{4} ; \mathrm{CCl}_{4}$ dosage group, $\gamma \mathrm{T}+\mathrm{CCl}_{4} ; \gamma$-Toc $+\mathrm{CCl}_{4}$ dosage group, $\mathrm{T} 3+\mathrm{CCl}_{4}$; $\mathrm{T} 3 \mathrm{mix}+\mathrm{CCl}_{4}$ dosage group (stained with hematoxylin-eosin; original magnification $\times 400$ ).

A)

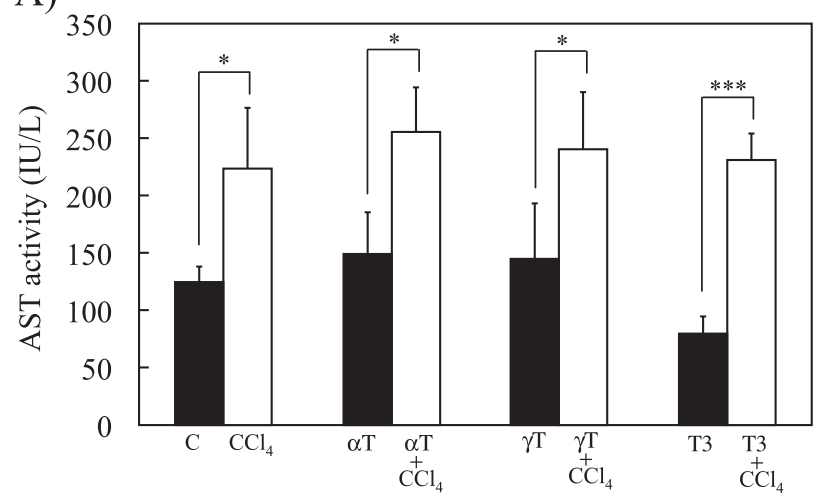

B)

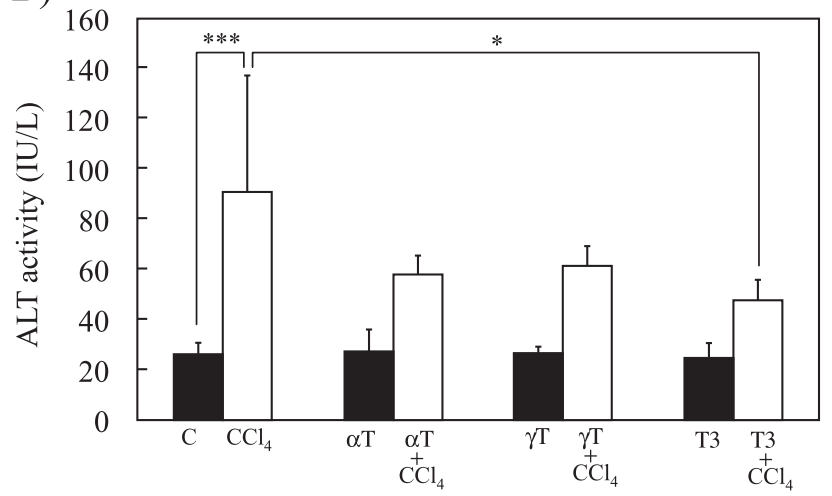

Fig. 3. Effects of vitamin E analogs on liver damage marker activity in plasma of rats administered CCl4; (A) Plasma AST activity. (B) Plasma ALT activity. Rats were fed a vitamin E-deficient diet for four weeks. After a $24 \mathrm{~h}$ fast, $20 \mathrm{mg}$ of each vitamin E analog was administered to the rats. Six hours later, a mixture of $\mathrm{CCl}_{4}$ and stripped corn oil $(1: 1,1 \mathrm{ml} / \mathrm{kg}$ body weight; $0.5 \mathrm{ml} / \mathrm{kg}$ body weight as $\mathrm{CCl}_{4}$ ) was administered orally to the rats. The control rats were given stripped corn oil alone as a placebo. Six hours after $\mathrm{CCl}_{4}$ administration, plasma samples were taken and the AST and ALT activities were measured. C; Control group, $\mathrm{CCl}_{4} ; \mathrm{CCl}_{4}$ dosage group, $\alpha \mathrm{T} ; \alpha$-Toc dosage group, $\alpha \mathrm{T}+\mathrm{CCl}_{4} ; \alpha$-Toc $+\mathrm{CCl}_{4}$ dosage group, $\gamma \mathrm{T} ; \gamma$-Toc dosage group, $\gamma \mathrm{T}+\mathrm{CCl}_{4}$; $\gamma$-Toc $+\mathrm{CCl}_{4}$ dosage group, T3; T3 mix dosage group, $\mathrm{T} 3+\mathrm{CCl}_{4} ; \mathrm{T} 3 \mathrm{mix}+\mathrm{CCl}_{4}$ dosage group. The values are mean $\pm \mathrm{SD}$ for 5 rats, ${ }^{*} p<0.05, * * * p<0.001$ (one-way ANOVA followed by Bonferroni post hoc test).

Expression of mRNA for inflammatory cytokines in liver

Expression of mRNA for tumor necrosis factor alpha (TNF- $\alpha$ ) and interleukin-1 (IL1)- $\beta$ in the liver was increased by administration of $\mathrm{CCl}_{4}$ (Fig. 4), suggesting that $\mathrm{CCl}_{4}$ administration caused inflammation of the liver parenchyma.
The expression of TNF- $\alpha$ and IL1- $\beta$ mRNA was increased further when $\gamma$-Toc was administered in such a state.

\section{Vitamin E analog contents of various tissues}

The $\alpha$-Toc content of liver and plasma was not changed 
A)

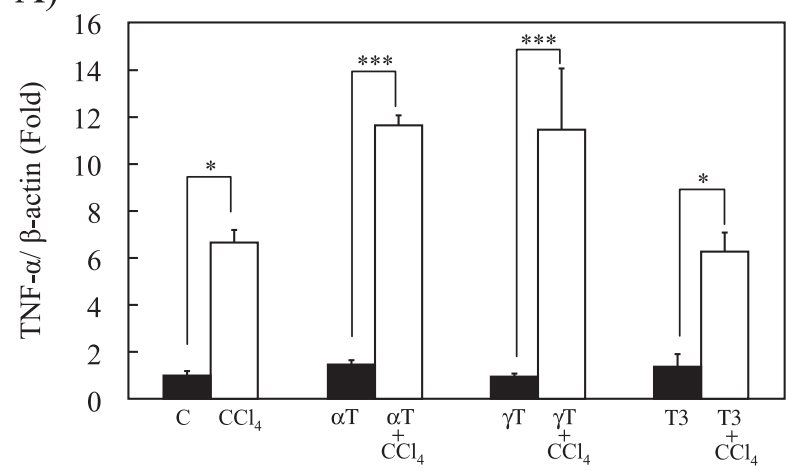

B)

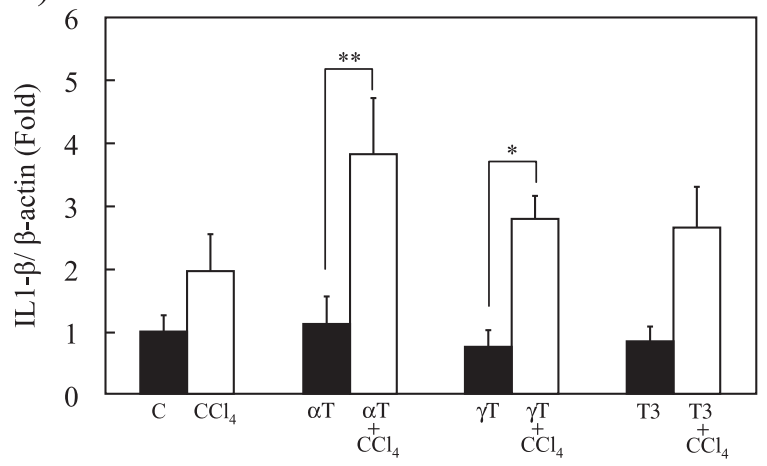

Fig. 4. Effects of vitamin $\mathrm{E}$ analogs on expression of inflammatory cytokine mRNAs in liver of rats administered CCl4; (A) Liver TNF- $\alpha$ mRNA expression. (B) Liver IL1- $\beta$ mRNA expression. Rats were fed a vitamin E-deficient diet for four weeks. After a $24 \mathrm{~h}$ fast, $20 \mathrm{mg}$ of each vitamin $\mathrm{E}$ analog was administered to the rats. Six hours later, a mixture of $\mathrm{CCl}_{4}$ and stripped corn oil $\left(1: 1,1 \mathrm{ml} / \mathrm{kg}\right.$ body weight; $0.5 \mathrm{ml} / \mathrm{kg}$ body weight as $\left.\mathrm{CCl}_{4}\right)$ was administered orally to the rats. The control rats were given stripped corn oil alone as a placebo. Six hours after $\mathrm{CCl}_{4}$ administration, the liver was removed and its expression of TNF- $\alpha$ and IL1- $\beta$ mRNAs was measured by real-time PCR. C; Control group, $\mathrm{CCl}_{4} ; \mathrm{CCl}_{4}$ dosage group, $\alpha \mathrm{T}$; $\alpha$-Toc dosage group, $\alpha \mathrm{T}+\mathrm{CCl}_{4} ; \quad \alpha$-Toc $+\mathrm{CCl}_{4}$ dosage group, $\gamma \mathrm{T} ; \gamma$-Toc dosage group, $\gamma \mathrm{T}+\mathrm{CCl}_{4} ; \gamma-\mathrm{Toc}+\mathrm{CCl}_{4}$ dosage group, T3; T3 mix dosage group, T3 $+\mathrm{CCl}_{4}$; $\mathrm{T} 3 \mathrm{mix}+\mathrm{CCl}_{4}$ dosage group. The values are mean $\pm \mathrm{SD}$ for 5 rats, ${ }^{*} p<0.05,{ }^{*} p<0.01,{ }^{* * *} p<0.001$ (one-way ANOVA followed by Bonferroni post hoc test).

by administration of $\mathrm{CCl}_{4}$. However, the $\gamma$-Toc content of the liver showed a tendency to decrease. On the other hand, the $\alpha$-T3 content of plasma was significantly decreased by $\mathrm{CCl}_{4}$ (Fig. 5). There were no significant differences in the quantity of vitamin $\mathrm{E}$ analogs in other tissues.

\section{Discussion}

In this study, we investigated the effects of $\gamma$-Toc and T3 on fatty liver induced by $\mathrm{CCl}_{4}$ in rats. At first, liver weight was increased in each group by administration of $\mathrm{CCl}_{4}$, thus confirming the induction of liver hypertrophy. As the TG content of the liver was also increased, this hypertrophy appeared to be caused by accumulation of TG. Because the increase in the liver TG content was suppressed by administration of T3, the latter may regulate lipid accumulation in the liver. Various hypotheses have been proposed to explain the mechanism of fatty liver induced by administration of $\mathrm{CCl}_{4}$. Recknagel et al. [10] suggested that $\mathrm{CCl}_{4}$ controls the secession of ribosome and liver proteosynthesis, and blocks lipoprotein secretion. In addition, the lipid accumulation is associated with deactivation of metabolizing enzymes. In fact, deactivation of various metabolic enzymes and a decrease of the P450 content in liver by administration of $\mathrm{CCl}_{4}$ have confirmed in both in vitro and in vivo systems $[11,12]$. Because lipid accumulation in the liver was inhibited by T3 administration, T3 play a role in lipoprotein synthesis and the transportation of lipids, and may possibly inhibit the deactivation of metabolic enzymes.

It is known that AST and ALT activity in plasma is increased by acute liver damage. In particular, plasma ALT activity increases as a result of destruction and necrosis of hepatocytes. As ALT activity was inhibited by administration of T3, hepatocyte necrosis may have been suppressed. It has been reported that $\alpha$-Toc ameliorates fatty liver damage induced by $\mathrm{CCl}_{4}$; ALT activity and the concentration of billirubin were lower, and liver fibrosis was inhibited in rats fed an $\alpha$-Toc-enriched diet [7]. In the present experiment, ALT activity tended to be lower in the $\gamma$-Toc group, and was significantly lower in the $\mathrm{T} 3$ group. Therefore, it is suggested that $\mathrm{T} 3$ suppresses the necrosis of hepatocytes by inhibition of $\mathrm{CCl}_{4}$-induced lipid peroxidation. It has reported that $\alpha$-T3 possesses 40-60 times higher antioxidant activity against oxidative damage than $\alpha$-Toc [13]. Consequently, we suggested that T3, especially $\alpha$-T3, restrained strongly lipid peroxidation in the liver than $\alpha$-Toc, and controlled lipid accumulation to the liver and cell death. A further examination is necessary for comparison of the effect of each $\mathrm{T} 3$ analog.

The $\alpha$-T3 content of plasma was decreased by administration of $\mathrm{CCl}_{4}$, whereas the liver $\alpha-\mathrm{T} 3$ content was unaffected. The $\alpha$-Toc is preferentially transported by $\alpha$-TTP in comparison with other vitamin $\mathrm{E}$ analogs, and is used for VLDL synthesis [5]. It is suggested that $\gamma$-Toc and T3 are accumulated in the liver and metabolized immediately. As it has been reported that $\mathrm{CCl}_{4}$ deactivates $\mathrm{CYP}$, we considered that the metabolism of vitamin $\mathrm{E}$ may be interrupted by $\mathrm{CCl}_{4}$, and that $\mathrm{T} 3$ may remain in the liver for a long time. Consequently, we suggest that $\mathrm{T} 3$ may trap trichloro radicals in the liver, and thus show antioxidant activity.

Kupper cells, which are fixed macrophages, are activated by liver damage, leading to production of inflammatory 
A)

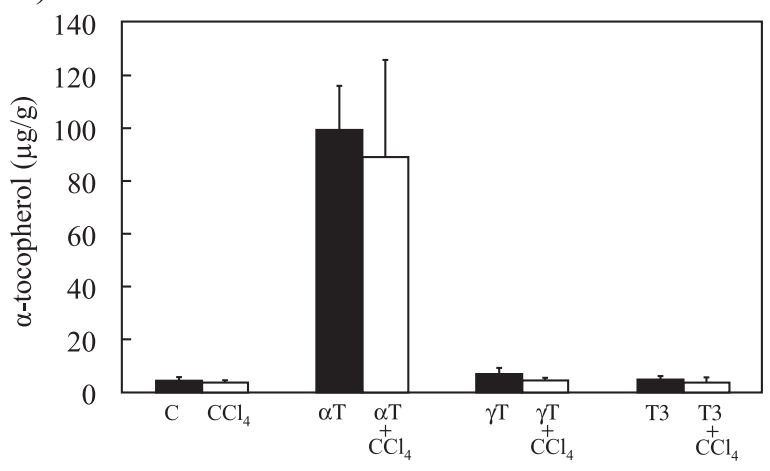

C)

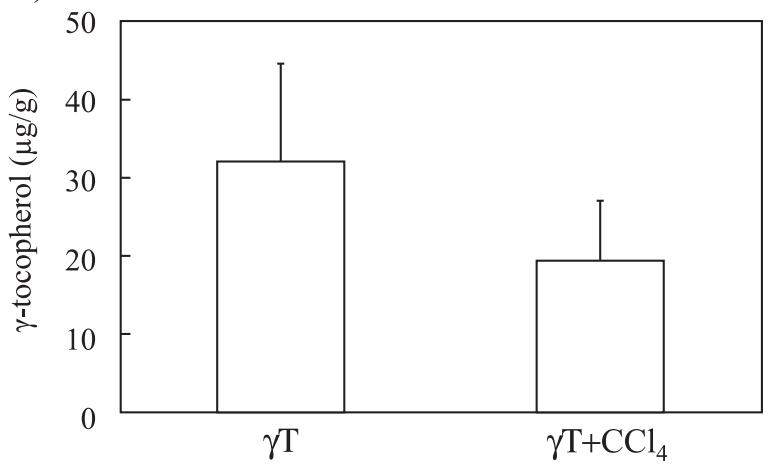

B)

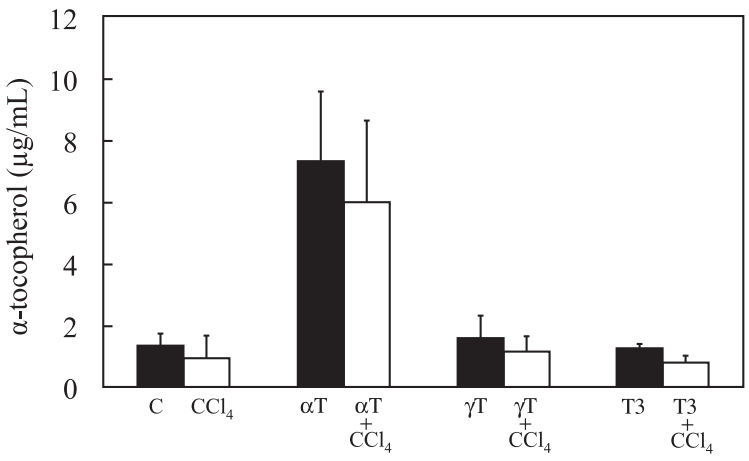

D)

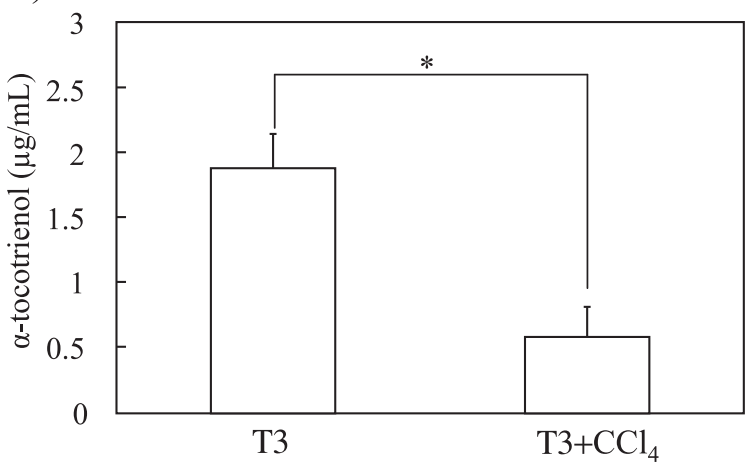

Fig. 5. Contents of individual vitamin $\mathrm{E}$ analogs in liver and plasma of rats administered $\mathrm{CCl}_{4}$; (A) Liver $\alpha$-Toc content. (B) Plasma $\alpha$-Toc content. (C) Liver $\gamma$-Toc content. (D) Plasma $\alpha$-T3 content. Rats were fed a vitamin E-deficient diet for four weeks. After a $24 \mathrm{~h}$ fast, $20 \mathrm{mg}$ of each vitamin $\mathrm{E}$ analog was administered to the rats. Six hours later, a mixture of $\mathrm{CCl}_{4}$ and stripped corn oil $\left(1: 1,1 \mathrm{ml} / \mathrm{kg}\right.$ body weight; $0.5 \mathrm{ml} / \mathrm{kg}$ body weight as $\left.\mathrm{CCl}_{4}\right)$ was administered orally to the rats. The control rats were given stripped corn oil alone as a placebo. Six hours after $\mathrm{CCl}_{4}$ administration, the liver and plasma were taken, and the quantity of each vitamin $\mathrm{E}$ analog was measured by HPLC. C; Control group, $\mathrm{CCl}_{4} ; \mathrm{CCl}_{4}$ dosage group, $\alpha \mathrm{T}$; $\alpha$-Toc dosage group, $\alpha \mathrm{T}+\mathrm{CCl}_{4} ; \alpha$-Toc $+\mathrm{CCl}_{4}$ dosage group, $\gamma \mathrm{T} ; \gamma$-Toc dosage group, $\gamma \mathrm{T}+\mathrm{CCl}_{4} ; \gamma$-Toc $+\mathrm{CCl}_{4}$ dosage group, T3; T3 mix dosage group, $\mathrm{T} 3+\mathrm{CCl}_{4}$; $\mathrm{T} 3 \mathrm{mix}+\mathrm{CCl}_{4}$ dosage group. The values are mean $\pm \mathrm{SD}$ for 5 rats, ${ }^{*} p<0.05$ (one-way ANOVA followed by Bonferroni post hoc test).

cytokines such as TNF- $\alpha$ and IL1- $\beta$. This inflammation spreads by stimulation of the endothelium, and leads to localized migration of monocytes and neutrophils. IL-6 is also produced by $\mathrm{T}$ cells. In the present study, we found that the expression of mRNA for inflammatory cytokines was drastically increased by $\mathrm{CCl}_{4}$. However, the vitamin $\mathrm{E}$ analogs T3, $\alpha$-Toc and $\gamma$-Toc, did not affect the expression of inflammatory cytokine mRNAs. Because the expression mRNAs for inflammatory proteins changes markedly in states of acute liver damage, further examination of this issue will be necessary.

Recently, the prevalence of non-alcoholic fatty liver disease (NAFLD) has been increasing in Japan. Nonalcoholic steatohepatitis (NASH), one of the conditions of NAFLD, was first reported by Ludwig et al. [14]. It is considered that fatty liver progresses further to NASH under conditions such as oxidative stress and the action of inflammatory cytokines. The histopathological picture in patients with NASH resembles that of alcoholic steato- hepatitis. However, this condition is harder to treat than alcoholic steatohepatitis, and can lead to liver cirrhosis or cancer. It has been reported that $\alpha$-Toc is effective for $\mathrm{NASH}$, and it has already been applied therapeutically. A report by Hasegawa et al. [15] indicated that ALT activity in the serum of NASH patients was reduced, and that the histopathological picture (fatty degeneration, inflammation, and fibrosis) was improved by administration of $\alpha$-Toc $(300 \mathrm{mg} /$ day $)$ for one year. Similar therapeutic application of $\gamma$-Toc and T3s is expected.

In summary, administration of vitamin $\mathrm{E}$ analogs has been shown to improve the liver damage induced by $\mathrm{CCl}_{4}$ in rats, and it is suggested that the improvement effect of T3s is stronger than that of $\gamma$-Toc. From reports that T3s are effective for treatment of NASH, similar effects are expected for these other vitamin $\mathrm{E}$ analogs. A further experiment is necessary for comparison of the effect of each T3 analog. Moreover, detailed examinations employing other models are planned. 


\section{Acknowledgments}

This work was supported by the grant from Eisai Food \& Chemical Co., Ltd.

\section{Abbreviations}

$\alpha$-Toc, $\alpha$-tocopherol; $\gamma$-Toc, $\gamma$-tocopherol; Toc3, tocotrienol; TG, triacylglycerol; T-Chol, total cholesterol.

\section{References}

[1] Recknagel, R.O.: Carbon tetrachloride hepatotoxicity. Pharmacol. Rev., 19, 145-208, 1967.

[2] Slater, T.F.: Necrogenic action of carbon tetrachloride in the rat: a speculative mechanism based on activation. Nature, 209, 36-40, 1966.

[3] Recknagel, R.O. and Ghoshal, A.K.: Lipoperoxidation as a vector in carbon tetrachloride hepatotoxicity. Lab. Invest., 15, 132-148, 1966.

[4] Yasusuke, M.: Learning toxicology from carbon tetrachlorideinduced hepatotoxicity. Yakugaku Zasshi, 126, 885-899, 2006.

[5] Traber, M.G., Burton, G.W., Hughes, L., Ingold, K.U., Hidaka, H., Malloy, M., Kane, J., Hyams, J., and Kayden, H.J.: Discrimination between forms of vitamin $\mathrm{E}$ by humans with and without genetic abnormalities of lipoprotein metabolism. J. Lipid Res., 33, 1171-1182, 1992.

[6] Iida, C., Fujii, K., Koga, E., Washino, Y., Kitamura, Y., Ichi, I., Abe, K., Matsura, T., and Kojo, S.: Effect of alphatocopherol on carbon tetrachloride intoxication in the rat liver. Arch. Toxicol., 83, 477-483, 2008.

[7] Maurizio, P., Gabriella, L., Fiorella, B., Emanuele, A., Maria,
E.B., Giuseppe, P., and Mario, U.D.: Vitamin E dietary supplementation protects against carbon tetrachlorideinduced chronic liver damage and cirrhosis. Hepatology, 16, 1014-1021, 1922.

[8] Ueda, T., Ichikawa, H., and Igarashi, O.: Determination of alpha-tocopherol stereoisomers in biological specimens using chiral phase high-performance liquid chromatography. $J$. Nutr. Sci. Vitaminol. (Tokyo), 39, 207-219, 1993.

[9] Folch, J., Lees, M., and Sloane Stanley, G.H.: A simple method for the isolation and purification of total lipides from animal tissues. J. Biol. Chem., 226, 497-509, 1957.

[10] Recknagel, R.O., Lombardi, B., and Schotz, M.C.: A new insight into pathogenesis of carbon tetrachloride fat infiltration. Proc. Soc. Exp. Biol. Med., 104, 608-610, 1960.

[11] Glende, E.A. Jr. and Recknagel, R.O.: Biochemical basis for the in vitro pro-oxidant action of carbon tetrachloride. Exp. Mol. Pathol., 11, 172-185, 1969.

[12] Rao, K.S. and Recknagel, R.O.: Early onset of lipoperoxidation in rat liver after carbon tetrachloride administration. Exp. Mol. Pathol., 9, 271-278, 1968.

[13] Serbinova, E., Kagan, V., Han, D., and Packer, L.: Free radical recycling and intramembrane mobility in the antioxidant properties of alpha-tocopherol and alpha-tocotrienol. Free Radic. Biol. Med., 10, 263-275, 1991.

[14] Ludwig, J., Viggiano, T.R., McGill, D.B., and Oh, B.J.: Nonalcoholic steatohepatitis: Mayo Clinic experiences with a hitherto unnamed disease. Mayo Clin. Proc., 55, 434-438, 1980.

[15] Hasegawa, T., Yoneda, M., Nakamura, K., Makino, I., and Terano, A.: Plasma transforming growth factor-beta1 level and efficacy of alpha-tocopherol in patients with nonalcoholic steatohepatitis: a pilot study. Aliment. Pharmacol. Ther., 15, 1667-1672, 2001. 